\title{
Selection and a 3-Year Field Trial of Sorangium cellulosum KYC 3262 Against Anthracnose in Hot Pepper
}

\author{
Sung-Chul Yun* \\ Department of Biomedical Sciences, Sun Moon University, Asan 330-744, Korea
}

(Received on January 14, 2014; Accepted on April 6, 2014)

KYC 3262 was selected as a biocontrol agent against anthracnose on hot pepper from 813 extracts of myxobacterial isolates. Dual culture with Colletotrichum acutatum and 813 myxobacterial extracts was conducted, and 19 extracts were selected that inhibited germination and mycelial growth of $C$. acutatum. All selections were Sorangium cellulosum, which are cellulolytic myxobacteria from soil. With the infection bioassay on detached fruits in airtight containers, KYC 3262, KYC 3512, KYC 3279, and KYC 3584 were selected. The listed four myxobacteria were cultured in CSG/1 liquid media, and harvested filtrates were sprayed on the infected fruits. KYC 3262 was selected from the studies of attached fruit in a greenhouse study. KYC 3262 filtrate was applied for 3 years (from 2011 to 2013) in a field study in Asan, Republic of Korea. Control values of the KYC 3262 in the field were $31 \%, 89 \%$, and $82 \%$ in 2011, 2012, and 2013, whereas values of the fungicide spray treatment were $19 \%, 97 \%$, and $91 \%$, respectively. Yields (kg/20 plants) of the KYC 3262 were 2.66 $\mathrm{kg}$ and $18.6 \mathrm{~kg}$ in 2011 and 2013, respectively, and those of the fungicide treatment were $2.0 \mathrm{~kg}$ and $20.2 \mathrm{~kg}$, in 2011 and 2013, respectively.

Keywords : antifungal activity, biocontrol, Colletotrichum acutatum, myxobacteria

Anthracnose is the most severe disease afflicting hot pepper. Researchers have been trying to control anthracnose by using biocontrol agents such as bacteria including Bacillus sp. (Park et al., 2006), Pantoea agglomerans (Jung et al., 2007), Pseudomonas koreensis (Kim et al., 2007), and Streptomyces griseofuscus (Lim, 2005), as well as the fungus Trichoderma harzianum (Žvković et al., 2010). Several

*Corresponding author.

Phone) +82-41-530-2282, FAX) +82-41-530-2939

E-mail)scyun@sunmoon.ac.kr trials have also been conducted evaluating myxobacteria. For example, Myxococcus fulvus inhibited mycelial growth of Colletotrichum gloeosporioides (Kim et al., 1998), but had no effect on anthracnose in hot pepper. Myxococcus sp. KYC 1126 showed antifungal activity against anthracnose (Colletotrichum acutatum) on hot pepper, but greater control was achieved with a fungicide in greenhouse and field trials (Kim and Yun, 2011a). As a rich source of novel bioactive secondary metabolites, myxobacteria have been evaluated (Bull et al., 2002; Gerth et al., 2003; Krug et al., 2008; Reichenbach, 2001). Bacteriolytic myxobacteria are known to produce agriculturally important antibiotics, and previous studies have suggested that Myxococcus sp. KYC 1126 may be the source of myxothiazol (Bartlett et al., 2002; Dawid, 2000).

In addition to bacteriolytic myxobacteria, cellulolytic myxobacteria have the unique ability to produce secondary metabolites with biological activity (Gerth, 2003). Reichenbach and Höfle (1994) reported that soraphen, a natural product of Sorangium cellulosum, had antifungal properties and completely inhibited apple scab fungi (Venturia inaequalis) and prevented grape gray mold (Botrytis cinerea). Other reports show that Spirodienal C from S. cellulosum has antifungal activity against $B$. cinerea, Botryosphaeria dothidea, and Sclerotinia sclerotiorum (Ahn, 2009). Although field trials have not been conducted, our previous results on gray mold in fruits showed that $S$. cellulosum KYC 3270, a cellulolytic myxobacterium, had antifungal activity against anthracnose fungus and $B$. cinerea (Kim and Yun, 2011b). However, biological control of cellulolytic myxobacteria against anthracnose on hot pepper has never been conducted in a field experiment. It is necessary to conduct field experiment because biocontrol agents may not be as efficient in the field, despite good efficiency under controlled conditions (Collange et al., 2011).

Since $C$. acutatum can infect green pepper fruits before harvest, infected fruits may or may not exhibit typical symptoms, making it difficult for growers to control. If a biological agent has a curative effect, it can be applied ac- 
cording to developed forecasting models, which is necessary when using curative fungicide applications (Kim et al., 2010). Therefore, one must select a biocontrol agent that has both preventive and curative abilities. The previously selected bacteriolytic myxobacterium KYC 1126 did not have a curative effect (Kim and Yun, 2011a), but the selected myxobacterial antagonist $S$. cellulosum KYC 3270 has shown both preventive and curative effects in the control of gray mold (Kim and Yun, 2011b). These results indicate the possibility of a new selected cellulolytic myxobacterium having a curative effect.

Based on the screening of more than eight hundreds of myxobacterial extracts by dual culture against anthracnose fungus, four cellulolytic myxobacterial were selected as antagonists to the pathogen. Liquid culture filtrates of the four-selected cellulolytic myxobacterial isolates were then prepared and tested in greenhouse and field experiments for 3 years. The objective of this study was to select a cellulolytic myxobacterium that has an antifungal activity of inhibiting mycelial growth and conidial germination of anthracnose fungus in vitro and to evaluate the biological activity of the selected antagonist in greenhouse and field studies in Asan, Republic of Korea.

\section{Materials and Methods}

Pathogens. The fungal pathogen Colletotrichum acutatum SM017 was identified (Yu and Yun, 2007) and isolated from field-grown hot pepper in Asan. C. acutatum was cultured on potato dextrose agar (PDA, Difco, Grand Island, NY) (24 g potato dextrose, $15 \mathrm{~g}$ agar/l) for 10 days at $25^{\circ} \mathrm{C}$ under fluorescent lamps with a $12 \mathrm{~h}$ light/dark period. Conidia of $C$. acutatum were collected from cultures using $2 \mathrm{ml}$ of sterile water. Colonies were then streaked on plates using a brush, and the mixtures of mycelia and conidia were filtered through four layers of cheesecloth. The concentration of the conidial suspension was adjusted to $1 \times 10^{5}$ conidia/ml using a light microscope (Eclipse 80i, Nikon, Tokyo, Japan) with a hemacytometer.

Myxobacterial extracts and culture filtrates. In total, 813 myxobacterial extracts were obtained from Myxobank (http://www.myxobank.or.kr/), which had been previously (extracted in each myxobacterial) isolated from South Korean soils between 2002 and 2008. Among these isolates, 455 consisted of 318 cellulolytic and 137 bacteriolytic myxobacteria that had been previously studied (Table 2; Kim and Yun, 2011b). Five hundred thirty-six isolates, or $65.9 \%$ of the tested extracts, were cellulolytic and identified as $S$. cellulosum. The remaining isolates were bacteriolytic myxobacteria and identified as Corallococcus spp., Myxococcus spp., Stigmatella spp., and Citrobacter sp., which comprised $19.4 \%, 12.9 \%, 0.4 \%$, and $0.1 \%$, respectively, of the total isolates tested. S. cellulosum extracts were provided from Myxobank and prepared with ST21CXP agar medium (Hyun et al., 2009). Crystals were obtained from 50 $\mathrm{ml}$ of the CSG/1 liquid medium and dissolved in dimethyl sulfoxide (DMSO) to make $1 \mathrm{ml}$ of myxobacterial extract. After selecting four isolates of cellulolytic myxobacteria (KYC 3512, 3584, 3279, and 3262), cell-cultured filter paper of the four isolates was cultured on ST21P agar medium and transferred to cell-cultured filter paper to CSG/1 liquid medium by shaking at $32^{\circ} \mathrm{C}$ to obtain liquid culture filtrates (Hyun et al., 2009).

Antagonism to mycelial growth and conidial germination in vitro. A dual culture assay for antagonism was conducted on PDA against $C$. acutatum with antagonistic myxobacterial extracts for 10 days. Mycelial agar plugs (5 $\mathrm{mm}$ in diameter) of the pathogen were placed in the middle of the PDA medium and $12 \mu \mathrm{l}$ of myxobacterial extract was placed on the mycelia for 7 to 10 days at $25^{\circ} \mathrm{C}$. Mycelial growth was then measured. Each replication consisted of three plates. The clear zone around conidia C. acutatum was examined to assess blocking of germination by myxobacterial extracts. To test for germination, a $250 \mu \mathrm{l}$ conidial suspension adjusted to $1 \times 10^{5}$ conidia $/ \mathrm{ml}$ was smeared on PDA plates, and an 8-mm paper disk with $12 \mu$ myxobacterial extract was placed in the middle of the culture and incubated in darkness for 7 days at $25^{\circ} \mathrm{C}$. The control was 12 $\mu 1$ DMSO on an 8-mm paper disk for each fungal culture. Diameter of the clear zone (no conidial germination) was measured. Among the tested myxobacterial extracts, 19 extracts with the greatest antifungal activity were selected based on least mycelial growth and largest clear zone (Table 1). To compare antagonistic activity against hot pepper anthracnose in the bioassays, dithianon (75\% active ingredient, wettable powder) was applied as a positive control.

Screening of 19 myxobacterial filtrates on detached fruit. A bioassay for antifungal activity of the selected 19 cellulolytic myxobacteria was conducted on hot pepper fruits. The surface of treated fruits was sterilized with $1 \%$ sodium hypochlorite for $2 \mathrm{~min}$ and washed twice with sterilized water. Prepared fruits were treated 5- $\mu 1$ drops of extract of the 19 cellulolytic myxobacteria with 50 times dilution after puncturing green pepper with a needle. Fruits were then inoculated with $3 \mu \mathrm{l}$ of conidial suspensions of anthracnose, and their symptoms were observed at 6 and 7 days after infection. The incidences of anthracnose and 
Table 1. The 19 myxobacterial extracts were selected based on the inhibition of mycelial growth and conidial germination of Colletotrichum acutatum. All extracts did not grow mycelium and inhibited conidial germination by showing a clear zone. The control value (\%) was tested using detached fruits treated with $5 \mu \mathrm{l}$ of the extracts at 50 times dilution after wound inoculation with the conidial suspension

\begin{tabular}{|c|c|c|c|c|c|}
\hline Number & Strain no. & $\begin{array}{l}\text { Isolated } \\
\text { location }\end{array}$ & Species name & $\begin{array}{c}\text { Clear } \\
\text { Zone }(\mathrm{mm})\end{array}$ & $\begin{array}{c}\text { Control } \\
\text { value }(\%)^{\mathrm{a}}\end{array}$ \\
\hline 1 & KYC3188 & Gyeryong & Sorangium cellulosum & 21.41 & 0.0 \\
\hline 2 & KYC3279 & Cheongwon & Sorangium cellulosum & 21.33 & 33.0 \\
\hline 3 & KYC3372 & Gimcheon & Sorangium cellulosum & 20.53 & 5.1 \\
\hline 4 & KYC3222 & Damyang & Sorangium cellulosum & 20.22 & 4.8 \\
\hline 5 & KYC3587 & Yongin & Sorangium cellulosum & 19.99 & 0.0 \\
\hline 6 & KYC3520 & Gongju & Sorangium cellulosum & 19.69 & 0.0 \\
\hline 7 & KYC3312 & Gimcheon & Sorangium cellulosum & 19.28 & 0.0 \\
\hline 8 & KYC3316 & Changnyeong & Sorangium cellulosum & 18.49 & 18.2 \\
\hline 9 & KYC3245 & Gimcheon & Sorangium cellulosum & 18.07 & 0.0 \\
\hline 10 & KYC3522 & Cheonan & Sorangium cellulosum & 18.06 & 3.7 \\
\hline 11 & KYC3299 & Geoje & Sorangium cellulosum & 17.83 & 12.4 \\
\hline 12 & KYC3114 & Amsepmg & Sorangium cellulosum & 17.79 & 0.0 \\
\hline 13 & KYC3249 & Geoje & Sorangium cellulosum & 17.60 & 0.0 \\
\hline 14 & KYC3584 & Yongin & Sorangium cellulosum & 17.50 & 38.0 \\
\hline 15 & KYC3204 & Changnyeong & Sorangium cellulosum & 17.04 & 29.4 \\
\hline 16 & KYC3261 & Goeje & Sorangium cellulosum & 16.68 & 31.0 \\
\hline 17 & KYC3512 & Buyeo & Sorangium cellulosum & 16.67 & 71.2 \\
\hline 18 & KYC3262 & Geoje & Sorangium cellulosum & 15.88 & 87.1 \\
\hline 19 & KYC3242 & Buyeo & Sorangium cellulosum & 15.82 & 30.8 \\
\hline
\end{tabular}

${ }^{\mathrm{a}}$ Control value $(\%)=($ Incidence on untreated medium - Incidence on treated medium $) /($ Incidence on untreated medium $) \times 100$

control values for the myxobacterium and the fungicide treatments were determined as follows:

Anthracnose incidence $(\%)=$ No. of diseased fruits $/$ Total no. of treated fruits $\times 100$;

Control value $(\%)=($ Incidence on untreated plot - Incidence on treated plot $) /($ Incidence on untreated plot $) \times 100$.

Following screening, four cellulolytic isolates were selected, KYC 3512, 3584, 3279, 3262, and liquid filtrates were prepared to use in the next experiment.

Bioassay with four selected cellulolytic myxobacteria. A bioassay for antifungal activity of myxobacteria KYC $3512,3584,3279$, and 3262 on hot pepper anthracnose was conducted on detached fruits in test tubes and pots in a greenhouse. The prepared culture filtrates of the four cellulolytic myxobacteria cultured in GSG/1 liquid medium were sprayed on detached green pepper fruit following surface sterilization with $70 \%$ ethanol. After treated fruits were air-dried for $12 \mathrm{~h}$, the conidial suspension was sprayed on the fruit with an airbrush until runoff. Each of the inoculated fruits was suspended inside a test tube with $4 \mathrm{~cm}$ diameter by the fruit stalk tied to a cross-shaped metal brace in the test tube opening. To maintain humid conditions inside the test tube, a piece of paper towel was soaked in sterile distilled water and placed at the bottom of the test tubes. After 7 to 10 days of inoculation, symptoms on the detached fruits were measured. To compare the selected myxobacterial extracts, dithianon was applied as a positive control. The control value was calculated in each treatment as described above.

Greenhouse experiment. A bioassay of the four selected myxobacteria in pots was conducted in a greenhouse located in Asan ( $36^{\circ} 47^{\prime} 57.45 \mathrm{~N}, 127^{\circ} 04^{\prime} 05.57 \mathrm{E}$ ) in July 2011. KYC 3262 was selected and tested in the greenhouse in July 2012. Seedlings of pepper cultivar (cv.) 'Supermannita' were grown until developing 10 or more green fruits. Fertilizer and pesticides for aphid control were applied as needed. In 2011, culture filtrates of KYC 3512, 3584, 3279, and 3262 were sprayed on the fruits until the filtrate ran off. Treated plants were dried for 1 day, and then $10^{6}$ conidia/ $\mathrm{ml}$ of suspension was sprayed onto treated fruits, and fruits were then placed in a 100\% relative humidity $(\mathrm{RH})$ incubator (Vision Korea, Suwon, Republic of Korea) for $24 \mathrm{~h}$ at $25^{\circ} \mathrm{C}$. Treated plants were grown in the greenhouse at $50 \%$ 
to $55 \% \mathrm{RH}$ and $25^{\circ} \mathrm{C}$ to $30^{\circ} \mathrm{C}$, and disease progress was observed for 14 to 21 days, with watering at 3-day intervals. As a positive control, $1 \mathrm{mg} / \mathrm{ml}$ dithianon was sprayed on plants, with three replications. Each treatment had more than 30 fruits and 4 to 5 pots. In 2012, the selected KYC 3262 was treated 1 day before and after inoculation to compare preventive and curative effects with those of the commercial fungicides. To determine preventive effects, the culture filtrate of KYC 3262 and dithianon were applied to the pots 1 day before the pathogen inoculation. KYC 3262 filtrate and tebuconazole were applied 1 day after the pathogen inoculation for the curative test. Three experiments were repeated in the greenhouse in 2012 using 10 or more plants for each treatment.

Field experiment. Bioassay for KYC 3262 in the field in Asan where was $100 \mathrm{~m}$ apart from the greenhouse was performed in 2011, 2012, and 2013. The three treatments consisted of an untreated control, a fungicide spray, and the myxobacteria KYC 3262 culture filtrate. Cultivar 'Supermannita' was chosen and transplanted on 10 May 2011, 12 May 2012, and 11 May 2013. Fungicides were sprayed alternatively at $0.5 \mathrm{mg} / \mathrm{ml}$ tebuconazole, $1 \mathrm{mg} / \mathrm{ml}$ dithianon, $0.5 \mathrm{mg} / \mathrm{ml}$ azoxystrobin, or $1 \mathrm{mg} / \mathrm{ml}$ chlorothalonil. The spray schedule was generally at 7 to 10 day intervals (Table 3). Insecticide was applied when needed, but was applied less than three times in each growing season. Each plot consisted of at least 90 plants, and 20 plants were selected early in the season for measurement of disease and yield. Disease incidence was the percentage of diseased fruits, and yield was the total fresh weight of red peppers of the selected 20 plants per plot. Anthracnose incidence was measured four times in 2011, two times in 2012, and seven times in 2013. Harvests were conducted three times each year. Weeds were controlled as needed using chemical and cultural methods.

\section{Results}

Myxobacterial extracts with antifungal activity. The myxobacterial extracts that completely inhibited mycelial growth and produced a clear zone by blocking the germination of $C$. acutatum were considered to have antifungal activity (Fig. 1). Of 536 cellulolytic extracts, 45 extracts blocked both $C$. acutatum germination and inhibited mycelial growth. Of 277 bacteriolytic extracts, only 11 exhibited antifungal activity. The cellulolytic myxobacteria had much more antifungal activity than the bacteriolytic myxobacteria (Fig. 1). Obviously, more cellulolytic extracts displayed antifungal activity when compared with bacteriolytic ex-

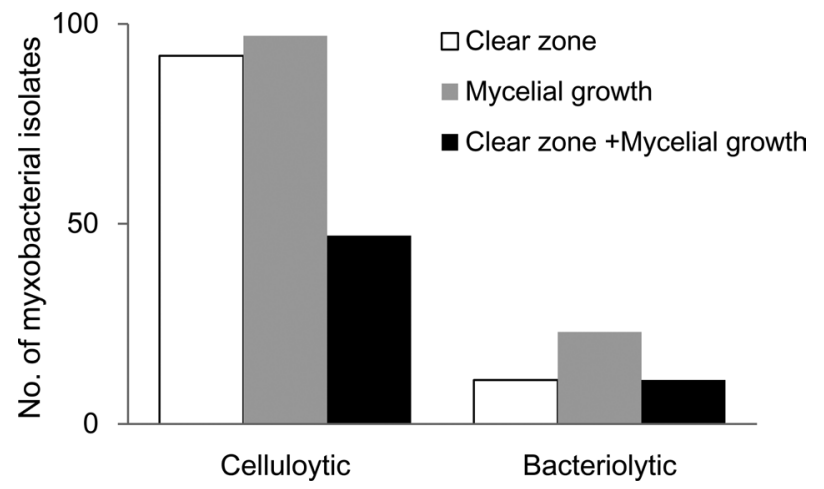

Fig. 1. The number of extracts showing antifungal activity among 536 cellulolytic and 227 bacteriolytic myxobacteria against $\mathrm{Col}$ letotrichum acutatum. The antifungal activity on dual culture was seen as a clear zone ( $\square$ ) due to the inhibition of conidial germination or complete lack of mycelial growth $(\square)$; isolates that simultaneously showed a clear zone and mycelial growth inhibition are designated as ( $\mathbf{\square})$.

tracts.

Antifungal effect on mycelial growth and spore germination of $C$. acutatum. The effect of the antagonists on mycelial growth could be divided into three levels: complete, delayed, and non-inhibition (Table 2). Of 536 cellulolytic myxobacterial extracts, $41.6 \%$ were non-inhibited, $40.3 \%$ were delayed, and only $18.1 \%$ completely inhibited the mycelial growth of $C$. acutatum. Among 277 bacteriolytic myxobacterial extracts, $82.7 \%$ did not inhibit the mycelial growth of C. acutatum, $8.3 \%$ completely inhibited mycelial growth, and $9 \%$ delayed growth. Blocking spore germination, as shown by a clear zone, was divided into four levels according to size (Table 2). Of 536 cellulolytic myxobacterial extracts, $82.8 \%$ of the cellulolytic myxobacterial extracts against $C$. acutatum had had no clear zone (Table 2). Only $1.1 \%$ had clear zones of 20 to $30 \mathrm{~mm}$ against $C$. acutatum, which was the most inhibited fungus. Among the tested 277 extracts of bacteriolytic myxobacteria, one extract blocked conidial germination with clear zones of $20 \mathrm{~mm}$ or more (Table 2).

Bioassay of 19 selected myxobacteria against anthracnose on detached fruit. After 5 days of inoculation with anthracnose conidial spraying, disease incidences on detached hot pepper fruits were examined. The incidence of anthracnose in the non-treated control was $85 \%$ after wound inoculation. Multiple comparisons among the tested 19 isolates were conducted on the final day of examination. The four lowest disease incidences among the filtrate treatments were with KYC 3279, 3584, 3512, and 3262, which 
Table 2. The number of myxobacterial extracts with antifungal activity against Colletotrichum acutatum. Antifungal activity was assessed as the inhibition of mycelial growth and a clear zone due to blocking of spore germination of the pathogens

\begin{tabular}{|c|c|c|c|c|c|c|c|c|}
\hline \multirow{2}{*}{$\begin{array}{c}\text { Myxobacterial } \\
\text { type }\end{array}$} & \multirow[b]{2}{*}{ Reference $^{\mathrm{a}}$} & \multicolumn{3}{|c|}{ Inhibition of mycelial growth } & \multicolumn{4}{|c|}{ Clear zone due to blocking of spore germination } \\
\hline & & $\begin{array}{l}\text { Complete } \\
\text { inhibition }\end{array}$ & $\begin{array}{l}\text { Delayed } \\
\text { growth }\end{array}$ & $\begin{array}{l}\text { Non- } \\
\text { inhibition }\end{array}$ & $20-30 \mathrm{~mm}$ & $10-20 \mathrm{~mm}$ & $<10 \mathrm{~mm}$ & None \\
\hline \multirow{3}{*}{ Cellulolytic } & Kim and Yun (2011a) & $29 / 318^{b}$ & $149 / 318$ & $140 / 318$ & $5 / 318$ & $41 / 318$ & $3 / 318$ & $269 / 318$ \\
\hline & In this study & $68 / 218$ & $67 / 218$ & $83 / 218$ & $1 / 218$ & $35 / 218$ & $7 / 218$ & $175 / 218$ \\
\hline & Subtotal & $97 / 536$ & $216 / 536$ & $223 / 536$ & $6 / 536$ & $76 / 536$ & $10 / 536$ & $444 / 536$ \\
\hline \multirow{3}{*}{ Bacteriolytic } & Kim and Yun (2011a) & $0 / 137$ & $3 / 137$ & $134 / 137$ & $0 / 137$ & $0 / 137$ & $0 / 137$ & $137 / 137$ \\
\hline & In this study & $23 / 140$ & $22 / 140$ & $92 / 140$ & $1 / 140$ & $2 / 140$ & $8 / 140$ & $129 / 140$ \\
\hline & Subtotal & $23 / 277$ & $25 / 277$ & $229 / 277$ & $1 / 277$ & $2 / 277$ & $8 / 277$ & $266 / 277$ \\
\hline
\end{tabular}

${ }^{a}$ Among the tested 813 myxobacterial extracts, 455 extracts were previously conducted by Kim and Yun (2011).

${ }^{b}$ Number of myxobacterial isolates showing each character among the tested isolates.

Table 3. Spray schedules for Sorangium cellulosum KYC 3262 culture filtrates and fungicides at the field in Asan. Sprays were generally applied at 7 to 10-day intervals. Dithianon (Di), tebuconazole (Te), azoxystrobin (Az), and chlorothalonil (Ch) were alternately sprayed. Before selection of KYC 3262 in 2011, fungicides were sprayed six times at a myxobacterium plot

\begin{tabular}{|c|c|c|c|c|c|}
\hline \multicolumn{2}{|c|}{2011 field trial } & \multicolumn{2}{|c|}{2012 field trial } & \multicolumn{2}{|c|}{2013 field trial } \\
\hline KYC 3262 & Fungicides & KYC 3262 & Fungicides & KYC 3262 & Fungicides \\
\hline $6 / 21(\mathrm{Az})$ & $6 / 21(\mathrm{Az})$ & $7 / 6(3262)$ & 7/6 (Di) & $6 / 26(3262)$ & 6/26 (Di) \\
\hline 6/30 (Di) & 6/30 (Di) & $7 / 13$ (3262) & $7 / 13(\mathrm{Te})$ & $7 / 3(3262)$ & $7 / 3(\mathrm{Az})$ \\
\hline 7/7 (Te) & 7/7 (Te) & $7 / 21(3262)$ & 7/21 (Ch) & $7 / 10(3262)$ & $7 / 10(\mathrm{Ch})$ \\
\hline 7/14 (Ch) & $7 / 14(\mathrm{Ch})$ & $7 / 27(3262)$ & $7 / 27(\mathrm{Az})$ & $7 / 17(3262)$ & 7/17 (Te) \\
\hline $7 / 25(\mathrm{Az})$ & $7 / 25(\mathrm{Az})$ & $8 / 3(3262)$ & 8/3 (Di) & $7 / 24(3262)$ & 7/24 (Di) \\
\hline 8/2 (Di) & 8/2 (Di) & $8 / 17(3262)$ & 8/17 (Te) & $7 / 31(3262)$ & 7/31 (Az) \\
\hline $8 / 10(3262)$ & $8 / 10(\mathrm{Te})$ & $8 / 24(3262)$ & 8/24 (Ch) & 8/7 (3262) & 8/7 (Ch) \\
\hline $8 / 19(3262)$ & 8/19(Ch) & $8 / 31(3262)$ & 8/31 (Az) & $8 / 14(3262)$ & 8/14 (Te) \\
\hline $8 / 26(3262)$ & $8 / 26(\mathrm{Az})$ & $9 / 6(3262)$ & 9/6 (Di) & $8 / 21(3262)$ & $8 / 21$ (Di) \\
\hline $9 / 2(3262)$ & 9/2 (Di) & $9 / 14(3262)$ & $9 / 14(\mathrm{Te})$ & $8 / 28(3262)$ & 8/28 (Az) \\
\hline 10 & 10 & 10 & 10 & 10 & 10 \\
\hline
\end{tabular}

had control values of $33 \%, 38 \%, 71 \%$, and $87 \%$, respectively, at 5 post-inoculation (Table 1). These cellulolytic isolates were selected to be used in the next experiment by preparing liquid culture filtrates.

Bioassay of the four selected myxobacteria against anthracnose on detached fruit. The culture filtrates of KYC 3279, 3584, 3512, and 3262 were sprayed on detached green pepper fruits. Control values of KYC 3262, 3279,3584 , and 3512 measured on the first day were $60 \%, 53.3 \%, 53.3 \%$, and $31.6 \%$, respectively (Fig. 2A). Control values of the myxobacteria were slightly lower than the dithianon control value of $61.6 \%$. On the second measured day, control values for KYC 3262, 3279, 3584, and 3512 were $57.7 \%, 43.6 \%, 40.4 \%$, and $25.9 \%$, respec- tively, and that of the positive control dithianon was $43.6 \%$ (Fig. 2A).

Greenhouse experiment against anthracnose in potted plants. Hot pepper plants with 10 or more green fruits were used to compare the four selected cellulolytic culture filtrates in the greenhouse at Asan in 2010. The control values with KYC 3262, 3279, 3584, and 3512 on the first measured day were $78.8 \%, 45.2 \%, 60.9 \%$, and $45.7 \%$, respectively. The control value for the commercial fungicide dithianon was $86.8 \%$ (Fig. 2B). Control values on the second measured day for KYC 3262, 3279, 3584, and 3512 were $59.2 \%, 45.5 \% 36.7 \%$, and $31.2 \%$, respectively, while that for dithianon was 55.1\%; KYC 3262 had slightly higher control values than the commercial fungicide (Fig. 2B). 

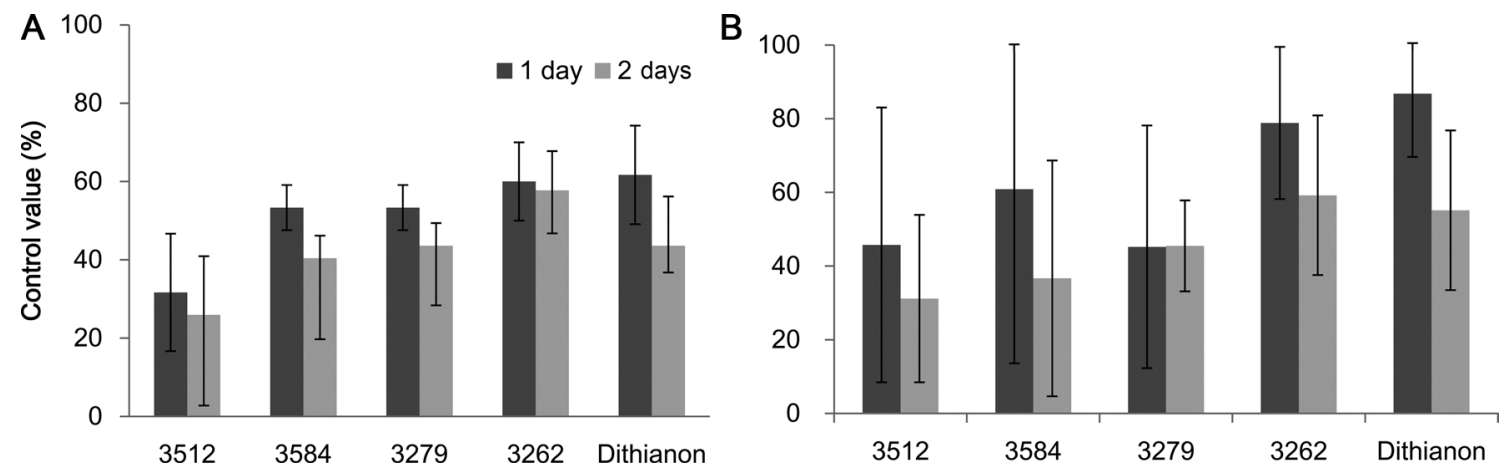

Fig. 2. Control values (\%) of anthracnose on detached hot peppers in test tubes (A) and attached pepper fruit in pots in the greenhouse (B) treated with the four culture filtrates of Sorangium cellulosum, KYC 3512, 3584, 3279, and 3262. As a negative control, a protective fungicide, dithianon, was sprayed $24 \mathrm{~h}$ before pathogen inoculation. Data bars show the averages of three replicates and error bars indicate standard errors. Anthracnose was measured for 2 days after symptoms first appeared.

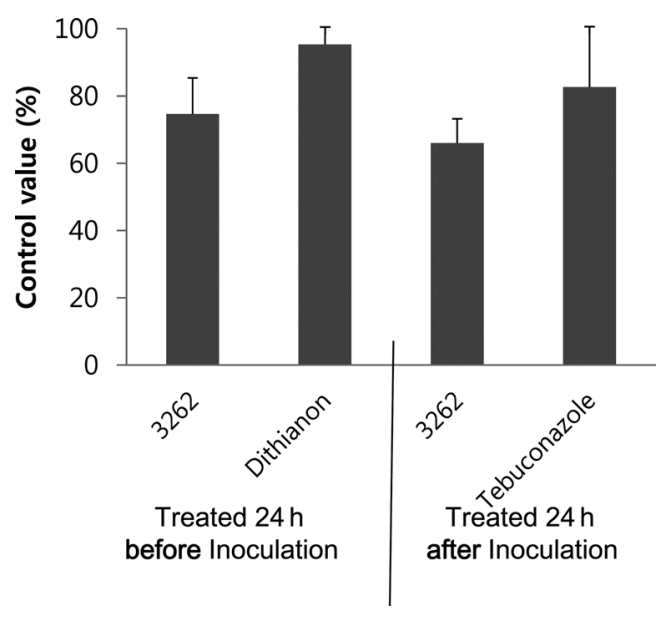

Fig. 3. Control values (\%) of anthracnose on attached pepper fruit in pots in the greenhouse treated with the CSG/1 liquid culture filtrates of Sorangium cellulosum KYC 3262 at $24 \mathrm{~h}$ before and after inoculation. To compare the commercial fungicides, a protective fungicide, dithianon, was sprayed at $24 \mathrm{~h}$ before inoculation and a curative fungicide, tebuconazole, was sprayed at $24 \mathrm{~h}$ after inoculation. Data bars show the averages of three replicates and error bars indicate standard errors.

To evaluate the preventive and curative effects of the selected KYC 3262, a greenhouse experiment was conducted in 2012. Disease incidence on the final measured day in the non-treated control was $46.6 \%$. The incidence with dithianon (a protective fungicide) was $2.0 \%$ after being treated $24 \mathrm{~h}$ before the pathogen inoculation, and the incidence with tebuconazole (a curative fungicide) was $7.3 \%$ after being treated $24 \mathrm{~h}$ after pathogen inoculation. The incidence rates with KYC 3262 at $24 \mathrm{~h}$ before and after inoculation were $12.3 \%$ and $16.3 \%$, respectively. Control values of KYC $326224 \mathrm{~h}$ before and after inoculation were $74.6 \%$ and $66.0 \%$, respectively, while the respective control values with dithianon and tebuconazole were $92.3 \%$ and $82.6 \%$ (Fig. 3).

Field experiment. KYC 3262 filtrate applications to control anthracnose in hot pepper were evaluated in the field from 2011 to 2013. Final disease incidence was $93 \%$ for unsprayed control plants, 64\% for KYC 3262 sprayed plants, and 75\% for fungicide sprayed plants in 2011 (Fig. $4 \mathrm{~A})$. The final disease incidence was $32 \%$ for unsprayed control plants, 3\% for KYC 3262 sprayed plants, and 1\% for fungicide sprayed plants in 2012 (Fig. 4B). In 2013, the final incidence was $27 \%$ for unsprayed control plants, $5 \%$ for KYC 3262 sprayed plants, and $2.5 \%$ for the fungicide sprayed plants (Fig. 4C). Control values for KYC 3262 were $31 \%, 89 \%$ and $82 \%$, and those for the fungicide were $19 \%, 97 \%$, and $91 \%$ in 2011,2012 , and 2013 , respectively (Fig. 4D). Obviously, the 93\% anthracnose incidence in 2011 in the unsprayed treatment was the highest disease incidence among the 3 years. The final yield of red pepper fruits from 20 plants at harvest were recorded three times in 2011 and 2013 (Fig. 5). The total yield of the 20 plants measured was $0.1 \mathrm{~kg}$ in the unsprayed control, $2.66 \mathrm{~kg}$ in the KYC 3262 treatment, and $2.0 \mathrm{~kg}$ in the fungicide treatment in 2009. In 2013, the total yield of the unsprayed control was $12.5 \mathrm{~kg}$ in the unsprayed control treatment, 18.6 $\mathrm{kg}$ in the KYC 3262 treatment, and $20.2 \mathrm{~kg}$ in the fungicide treatment.

\section{Discussion}

Among the 813 myxobacterial extracts tested, 223 had antifungal activity that completely inhibited mycelial growth and produced a clear zone by blocking spore germination 
A

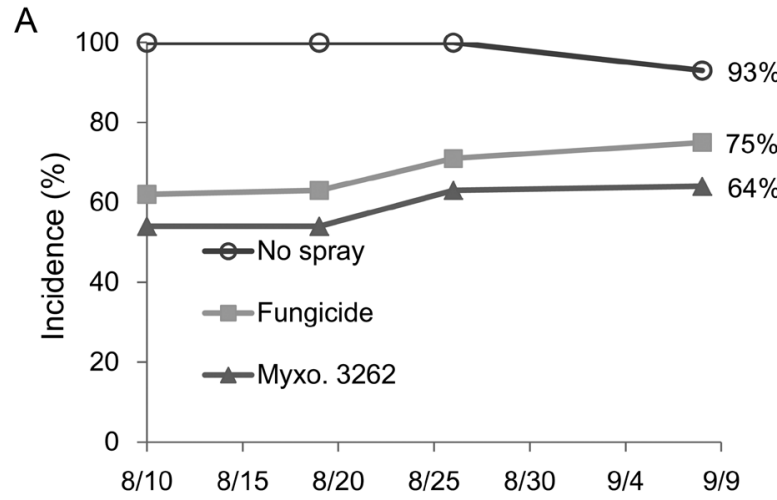

C

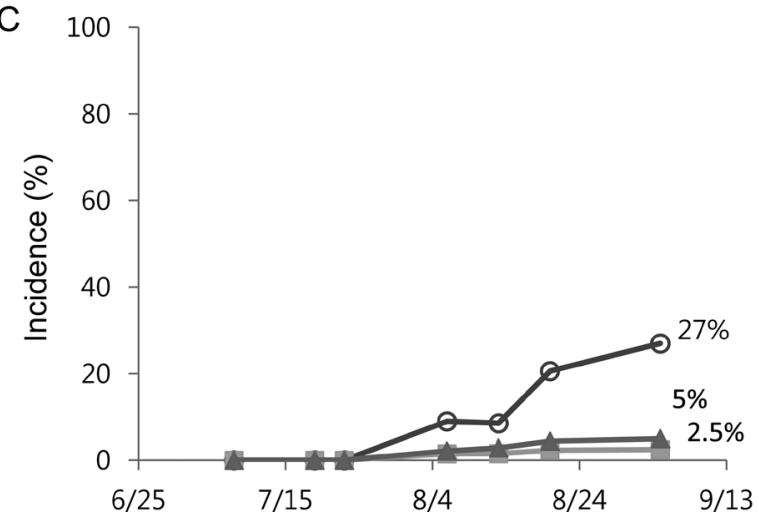

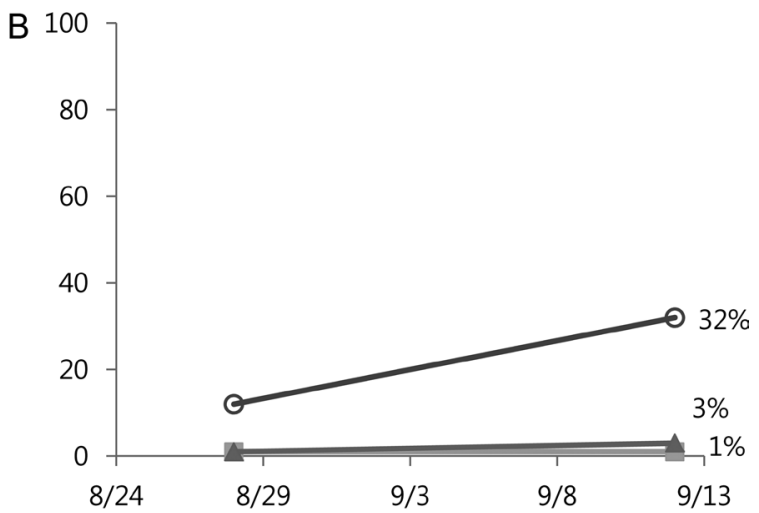

D 100

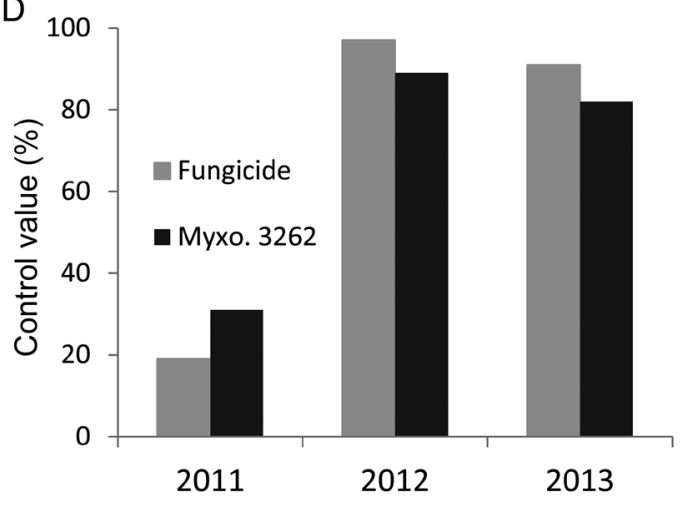

Fig. 4. Anthracnose progress in the field for three treatments: unsprayed control (०), Sorangium cellulosum KYC 3262 (๘), and fungicide $(\diamond)$ in 2011 (A), 2012 (B), and 2013 (C). Each treatment had a plot. Disease incidence was calculated as a percentage of diseased fruits among 20 plants. Control values of several fungicides ( $\square$ ) and S. cellulosum KYC 3262 (घ) from 2011 to 2013 (D).

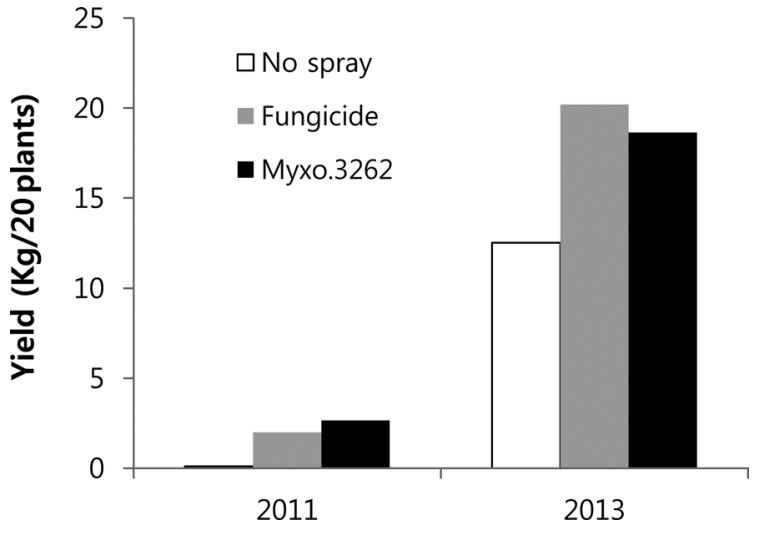

Fig. 5. Yields of fresh, healthy red peppers from the three treatments: unsprayed control ( $\square$ ), fungicide ( $\square$ ), and Sorangium cellulosum KYC 3262 (-) in 2011 and 2013 in the Asan field. Pepper yields were obtained from 20 plants per treatment.

on C. acutatum. Only 11 of 277 bacteriolytic isolates had a clear zone due to inhibited conidial germination, and 92 of 536 cellulolytic extracts attained a clear zone. Of the total 536 cellulolytic myxobacteria, $18 \%$ completely inhibited mycelial growth, whereas only $8.3 \%$ of 277 bacteriolytic myxobacteria inhibited growth. In terms of antifungal activity against anthracnose fungus, cellulolytic myxobacteria performed better than bacteriolytic myxobacteria.

Our previous study showed that bacteriolytic Myxococcus sp. KYC 1126 has effective antagonistic activity against anthracnose on hot pepper, justifying the comparison between previously selected bacteriolytic KYC 1126 and currently selected cellulolytic KYC 3262 myxobacteria (Kim and Yun, 2011a). Both myxobacteria completely inhibited mycelial growth. Control values for KYC 1126 in pot experiments were $60 \%$ in 2009 and $61.3 \%$ in 2010 (Kim and Yun, 2011a). Control values for KYC 3262 in pot experiments in 2011 and 2012 were $78.8 \%$ and $74.6 \%$, respectively (Fig. 2B and Fig. 3). Additionally, control values for KYC 1126 in field experiments in 2009 and 2010 were $13.6 \%$ and $41.0 \%$, respectively, and those for KYC 3262 in 2011,2012 , and 2013 were $31.2 \%, 90.6 \%$ and $81.5 \%$, respectively. Control values in the field seem to be more dependent on the incidence of the disease in unsprayed controls. That is, if disease pressure in a particular year is severe, control values tend to be low in both the fungicide and antagonist treatments. However, control values with 
KYC 3262 in this study were higher than those with KYC 1126 in both greenhouse and field experiments in Asan over several years.

In the greenhouse, spraying KYC 3262 culture filtrates 1 day before and after inoculation showed that the selected antagonist had both protective and curative effects $(75 \%$ and $66 \%$, respectively), even though control values were $18 \%$ and $16 \%$ lower than dithianon and tebuconazole, respectively (Fig. 3). Because KYC 3262 inhibited both the conidial germination and mycelial growth of $C$. acutatum, we speculated that $S$. cellulosum KYC 3262 has both protective and curative effects against anthracnose. Antagonists must inhibit spore germination and hyphal growth both before and after infection (Choi et al., 2006). In previous studies, bacteriolytic KYC 1126 showed only a protective effect rather than curative effect on hot pepper anthracnose in pot experiments (Kim and Yun, 2011a).

Although the target pathogen $B$. cinerea was different, the selected cellulolytic myxobacteria KYC 3270 had both preventive and curative effects in the control of gray mold latent infections (Kim and Yun, 2011b). During the selection of KYC 3262 using detached fruit and pot experiments, the final four isolates, KYC 3512, 3584, 3279, and 3262 , showed antifungal activities similar to the commercial fungicide dithianon. Although KYC 3262 had slightly higher antifungal activity than the other three isolates, KYC 3584 or 3279 can also be used as an alternate antagonist. This indicates that biocontrol by cellulolytic myxobacteria has many alternative isolates to choose antagonists, and provides simple and effective strategies for controlling anthracnose in hot pepper. Although most research on bioactivity has been conducted on bacteriolytic myxobacteria (Bull et al., 2002; Chung et al., 2008; Kim and Yun, 2011a; Kim et al., 1998; Kim et al., 2003; Krug et al., 2008), cellulolytic myxobacteria need to be further studied due to their superior antifungal activity, as well as their curative activity toward bacteriolytic myxobacteria.

As the field trials of KYC 1126 showed that a 10-day interval between myxobacteria application was too long to protect from natural infection in the field, 7-day intervals were conducted in both myxobacterial and fungal treatments in the field from 2011 to 2013. In 2012, it had severe drought periods right after transplanting for a month. In addition, it was too high disease pressure to harvest hot pepper fruits at the all three treatments plots.

It is difficult to compare antifungal activity between KYC 3262 and KYC 3270 because the former was selected for $C$. acutatum and the latter for $B$. cinerea. The control value of KYC 3270 against gray mold on strawberry was $79 \%$ to $85 \%$ in an airtight box experiment, and the control value of KYC 3262 against anthracnose on hot pepper was $60 \%$ in a test tube experiment (Fig. 2A). Considering that the control value of dithianon was $61.6 \%$ on pepper anthracnose, the selected cellulolytic myxobacterium in this study performed as well as the commercial fungicide.

Recently, S. cellulosum was divided into five subgroups and each group had a putative metabolite (Lee et al., 2013). Ambruticin and soraphen were potential antimicrobial secondary metabolites which were belong to group D and E, respectively. Since our selected four isolates, KYC 3262, 3512, 3584, and 3279 were not tested for subgrouping studies, we had no idea either ambruticin or soraphen had antimicrobial activities on C. accutatum. Nonetheless, it is reasonable to speculate that either ambruticin or soraphen had an antifungal activity against anthracnose and necessary to investigate chemical study with our selected isolates.

Without 10 or more fungicide applications to their fields, farmers cannot harvest hot peppers in Korea due to anthracnose damage. Similar to the development of Phytophthoraresistant varieties against Phytophthora blight, breeding for anthracnose on hot pepper has not been available until now. Safer and more eco-friendly alternatives to synthetic fungicides are needed to provide more effective and acceptable control of anthracnose in hot pepper. Our results show that the selected myxobacterium KYC 3262 provides a promising new method of anthracnose control.

\section{References}

Ahn, J. W. 2009. Spirodienal C, a new spiroketal produced by Sorangium cellulosum (Myxobacteria). Bull. Korean Chem. Soc. 30:1218-1220.

Bartlett, D. W., Clough, J. M., Godwin, J. R., Hall, A. A., Hamer, M. and Dobrzanski, B. P. 2002. The strobilurin fungicides. Pest Manag. Sci. 58:649-662.

Bull, C. T., Shetty, K. G. and Subbarao, K. V. 2002. Interactions between myxobacteria, plant pathogenic fungi, and biocontrol agents. Plant Dis. 86:889-896.

Choi, Y. H., Kim, H. T., Kim, J. C., Jang, K. S., Cho, K. Y. and Choi, G. J. 2006. In Vitro antifungal activities of 13 fungicides against pepper anthracnose fungi. Kor. J. Pest. Sci. (in Korean) 10:36-42.

Chung, J. W., Lee, C. Y., Yun, S. C. and Cho, K. Y. 2008. Screening of myxobacteria inhibiting the growth of Collectotrichum acutatum causing anthracnose on pepper. Kor. J. Microbiol. Biotechnol. (in Korean) 36:21-27.

Collange, B., Navarrete, M., Peyre, G., Mateille, T. and Tchamitchian, M. 2011. Root-knot nematode (Meloidogyne) management in vegetable crop production: The challenge of an agronomic system analysis. Crop Prot. 30:1251-1262.

Dawid, W. 2000. Biology and global distribution of myxobacteria 
in soils. FEMS Microbiol. Rev. 24:403-427.

Gerth, K., Pradella, S., Perlova, O., Beyer, S and Müller, R. 2003. Myxobacteria: proficient producers of novel natural products with various biological activities-past and future biotechnological aspects with the focus on the genus Sorangium. J. Biotechnol. 102:233-253.

Hyun, H. S., Chung, J. W., Lee, H. B.,Youn, J. K., Lee, C. Y., Kim, D. H. and Cho, K. Y. 2009. Isolation of cellulosedegrading myxobacteria Sorangium cellulosum. Kor. J. Microbiol. (in Korean) 45: 48-53.

Jung, H. I., Kim, K. K., Park, H. C., Lee, S. M., Kim, Y. G., Kim, H. S., Lee, C. Y. and Son, H. J. 2007. Isolation and characteristics of bacteria showing biocontrol and biofertilizing activities. Kor. J. Life Sci. (in Korean) 17:1682-1688.

Kim, B. S., Anh, J. W. and Cho, K. Y. 1998. Isolation and identification of myxobacteria KR025 and searching of their bioactive compounds. Kor. J. Plant Pathol. (in Korean) 14:345349.

Kim, S. T., Ahn, M. I. and Yun, S. C. 2010. Evaluation of anthracnose forecaster of an integrated pest management system on hot pepper in the fields. Res. Plant Dis. (in Korean) 16:6673.

Kim, S. T. and Yun, S. C. 2011a. Biocontrol with Myxococcus sp. KYC 1126 against anthracnose in hot pepper. Plant Pathol. J. 27:156-163.

Kim, S. T. and Yun, S. C. 2011b. Selection of KYC 3270, a cellulolytic myxobacteria of Sorangium cellulosum, against several phytopathogens and a potential biocontrol agent against gray mold in stored fruit. Plant Pathol. J. 27:257-265.

Kim, Y. S., Bae, W. C. and Baek, S. J. 2003. Bioactive substances from myxobacteria. Kor. J. Microbiol. Biotechnol. 31:1-12.

Kim, Y. S., Cho, Y. J., Kim, S. W., Kim, Y, J., Min, J. S. and Lee,
Y. S. 2007. Studies of antagonistic bacteria against pepper anthracnose pathogen Collectotrichum species. Kor. J. Agr. Sci. 18:97-104.

Krug, D., Zurek, G., Revermann, O., VosMichiel, V. G. J. and Müller, R. 2008. Discovering the hidden secondary metabolome of Myxococcus xanthus: a study of intraspecific diversity. App. Envir. Microbiol. 74:3058-3068.

Lee, C., An, D., Lee, H. and Cho, K. 2013. Correlation between Sorangium cellulosum subgroups and their potential for secondary metabolite production. J. Microbiol. Biotechnol. 23:297-303.

Lim, T. H. 2005. Antifungal activity of Streptomyces griseofuscus 200401 against pathogens causing late blight and anthracnose on pepper. J. Pest. Sci. 9:102-107.

Park, S. M., Jung, H. J. and Yu, T. S. 2006. Screening of an antagonistic bacterium for control of red-pepper anthracnose, Colletotrichum gloeosporioides. Kor. J. Life Sci. (in Korean) 16:420-426.

Reichenbach, H. 2001. Myxobacteria, producers of novel bioactive substances. J. Industrial Microbiol. Biotech. 27:149-156.

Reichenbach, H. and Höfle, G. 1994. Discovery of a new antifungal mechanism of action: soraphen- an almost-success story. Scientific Annual Report, Gesellschaft für Biotechnologische ForschungmbH. Braunschweig, pp. 5-22.

Yu, M. Y. and Yun, S. C. 2007. Morphological and molecular identification of anthracnose Collectotrichum spp. from Chungnam field in 2005. Sun Moon J. Nat. Sci. 8:59-67.

Žvković, S., Stojanović, S., Ivanović, Ž.,Gavrilović, V., Popović, T. and Balaž, J. 2010. Screening of antagonistic activity of microorganisms against Colletotrichum acutatum and Colletotrichum gloeosporioides. Arch. Biol. Sci. Belgrade. 62:611623. 